\title{
Perforated Blind Pouch: An Unusual Late Complication Following Lateral Anastomosis After a Right Hemicolectomy
}

Bishal Pal ${ }^{1}$, Souradeep Dutta ${ }^{1}$, Ankit Jain ${ }^{1}$, Abhinaya Reddy ${ }^{1}$, Vishnu Prasad Nelamangala Ramakrishnaiah ${ }^{1}$

1. Surgery, Jawaharlal Institute of Postgraduate Medical Education and Research, Puducherry, IND

Corresponding author: Vishnu Prasad Nelamangala Ramakrishnaiah, vprasad285@gmail.com

\begin{abstract}
Blind loop syndrome (BLS) is a well-recognized delayed complication in small bowel strictures, stenosis, fistulas, diverticula, or post-gastrectomy afferent loop syndrome. However, due to its delayed presentation, BLS after side-to-side bowel anastomosis is inadequately reported. The vicious cycle of the blind loop is due to bacterial overgrowth, resulting in diarrhea, weight loss, malnutrition, and rarely mucosal erosion, bleeding, and perforation peritonitis. Diagnosis of BLS requires knowledge of previous surgery performed, a high level of clinical suspicion, and experienced radiological abilities. In this case report, we present the clinico-radiological profile of a 54-year-old diabetic patient with a perforated blind ileal pouch occurring four years after a right hemicolectomy with side-to-side ileo-transverse anastomosis.
\end{abstract}

Review began 05/12/2021 Review ended 05/13/2021 Published 05/15/2021

\section{(c) Copyright 2021}

Pal et al. This is an open access article distributed under the terms of the Creative Commons Attribution License CC-BY 4.0., which permits unrestricted use, distribution, and reproduction in any medium, provided the original author and source are credited.
Categories: Gastroenterology, General Surgery

Keywords: blind pouch syndrome, blind pouch, bacterial peritonitis, blind loop syndrome, micro-perforation, gastrointestinal perforation

\section{Introduction}

"Blind loop syndrome" (BLS) and related complications due to intestinal overgrowth and abnormal peristalsis in the blind pouch are well recognized. BLS has been more commonly reported in small bowel strictures, stenosis, fistulas, diverticula, or after post-gastrectomy afferent loop syndrome $[1,2]$. However, due to its delayed presentation, BLS is rarely reported following a side-to-side intestinal anastomosis. Thus, its actual incidence after the side-to-side intestinal anastomosis is unknown. Here, we present the clinicoradiological features of a diabetic patient presenting with blind pouch perforation following a side-to-side ileo-transverse anastomosis.

\section{Case Presentation}

A 54-year-old diabetic gentleman presented with severe diffuse abdominal pain with abdominal distension for four days, followed by diarrhea and fever with chills for two days. He had undergone a right hemicolectomy for carcinoma cecum in a different hospital four years back. Postoperative biopsy reported well-differentiated adenocarcinoma with pathological staging - T4N2M0. He received eight cycles of adjuvant capecitabine and oxaliplatin, following which he was under six-monthly follow-up with no recurrence.

On examination, he was conscious, oriented, and dehydrated. He had tachycardia (110/min) with a blood pressure of 130/70 $\mathrm{mm}$ of $\mathrm{Hg}$. The abdomen was distended, with diffuse tenderness and signs of peritonitis. His blood glucose at the time of presentation was $550 \mathrm{mg} / \mathrm{dl}$ with no ketoacidosis. Blood investigations showed hemoglobin of $13 \mathrm{gm} / \mathrm{dl}$, total counts of $7600 / \mathrm{mm}^{3}$ with $81 \%$ neutrophils, platelet counts were 2.2 lacs $/ \mathrm{mm}^{3}$, urea of $41 \mathrm{mg} / \mathrm{dl}$, creatinine of $0.67 \mathrm{mg} / \mathrm{dl}$, sodium of $138 \mathrm{mEq} / \mathrm{dl}$, and potassium of $3.58 \mathrm{mEq} / \mathrm{dl}$. An erect chest X-ray showed a thin rim of pneumoperitoneum under the right hemidiaphragm (Figure 1). 


\section{Cureus}

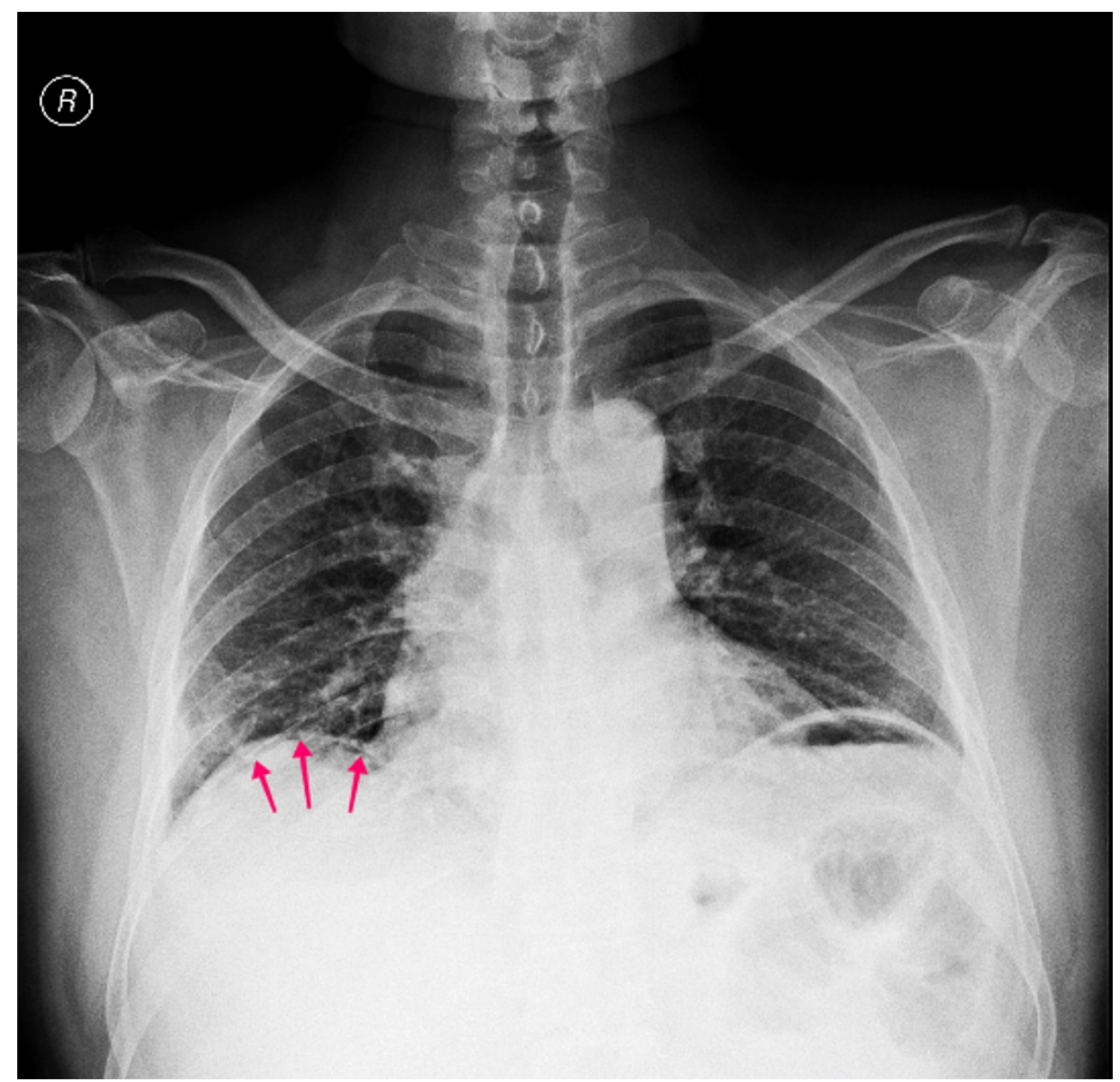

FIGURE 1: Chest X-ray showing a thin rim of air under the right diaphragm (red arrows).

A contrast-enhanced computed tomography (CECT) was done, which showed scattered foci of pneumoperitoneum, and edematous thickened ileal loop distal to the ileo-transverse anastomosis with a small collection with air foci within it, mesenteric fat stranding but no free fluid abdomen. The anastomotic site was healthy with no abnormal thickening suggestive of recurrence (Figure 2). 


\section{Cureus}
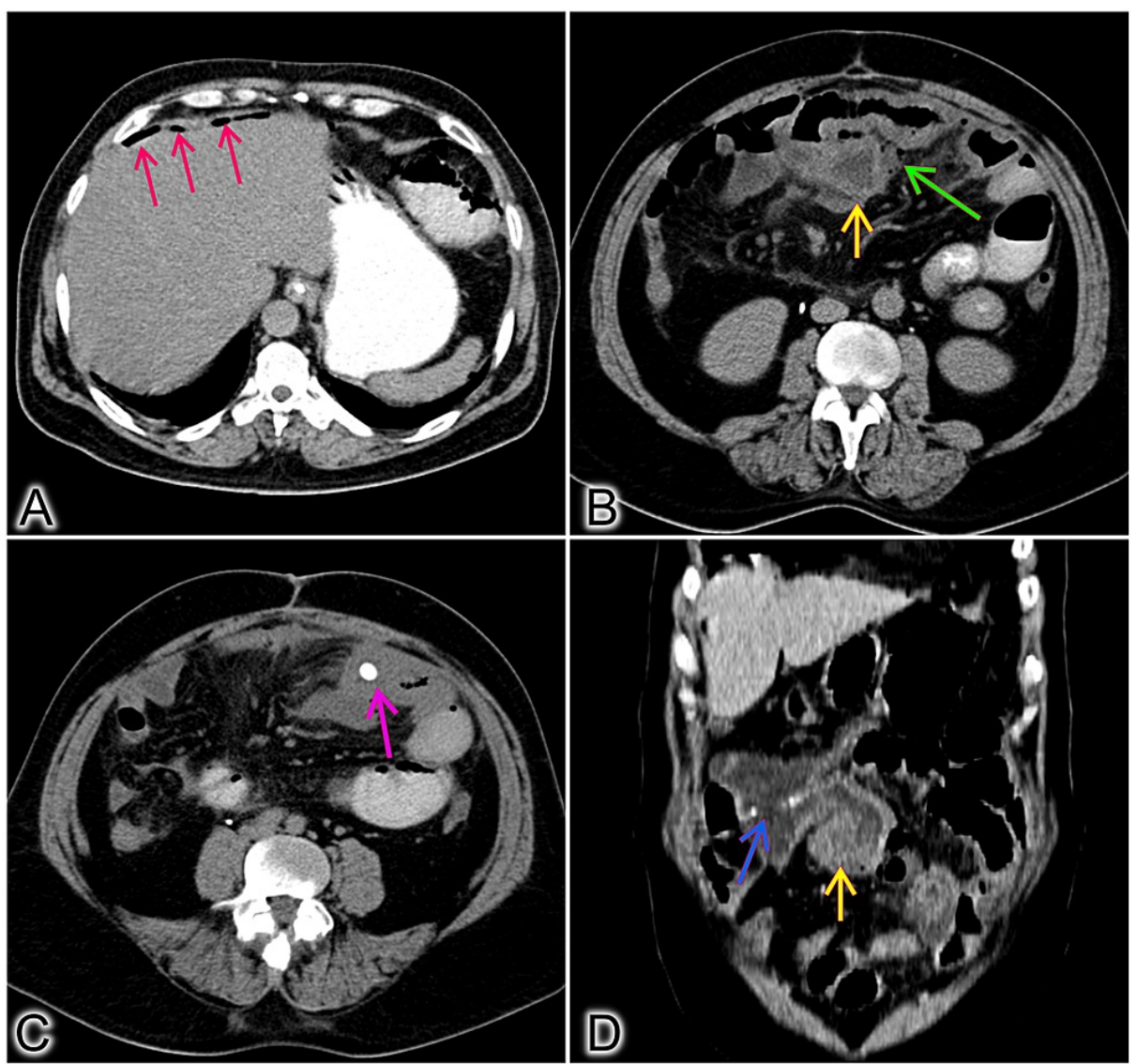

FIGURE 2: CT images. (A) Red arrows showing specs of intra-abdominal air. (B) Yellow arrow shows the thickened inflamed blind ileal loop, green arrow shows extra-luminal air with collection adjacent to the blind loop. (C) Enterolith seen in the colonic blind loop portion. (D) Coronal section showing the thickened ileal loop (yellow arrow) and the ileotransverse lateral anastomosis (blue arrow).

After the initial resuscitation, he was taken up for an exploratory laparotomy. Intraoperatively, an

unhealthy, thickened, distended ileal blind loop of length $8 \mathrm{~cm}$ with a sloughed-off portion of the bowel wall covered with pus flakes with a pinpoint micro-perforation, distal to the side-to-side ileo-transverse colon anastomosis (Figure 3). 


\section{Cureus}

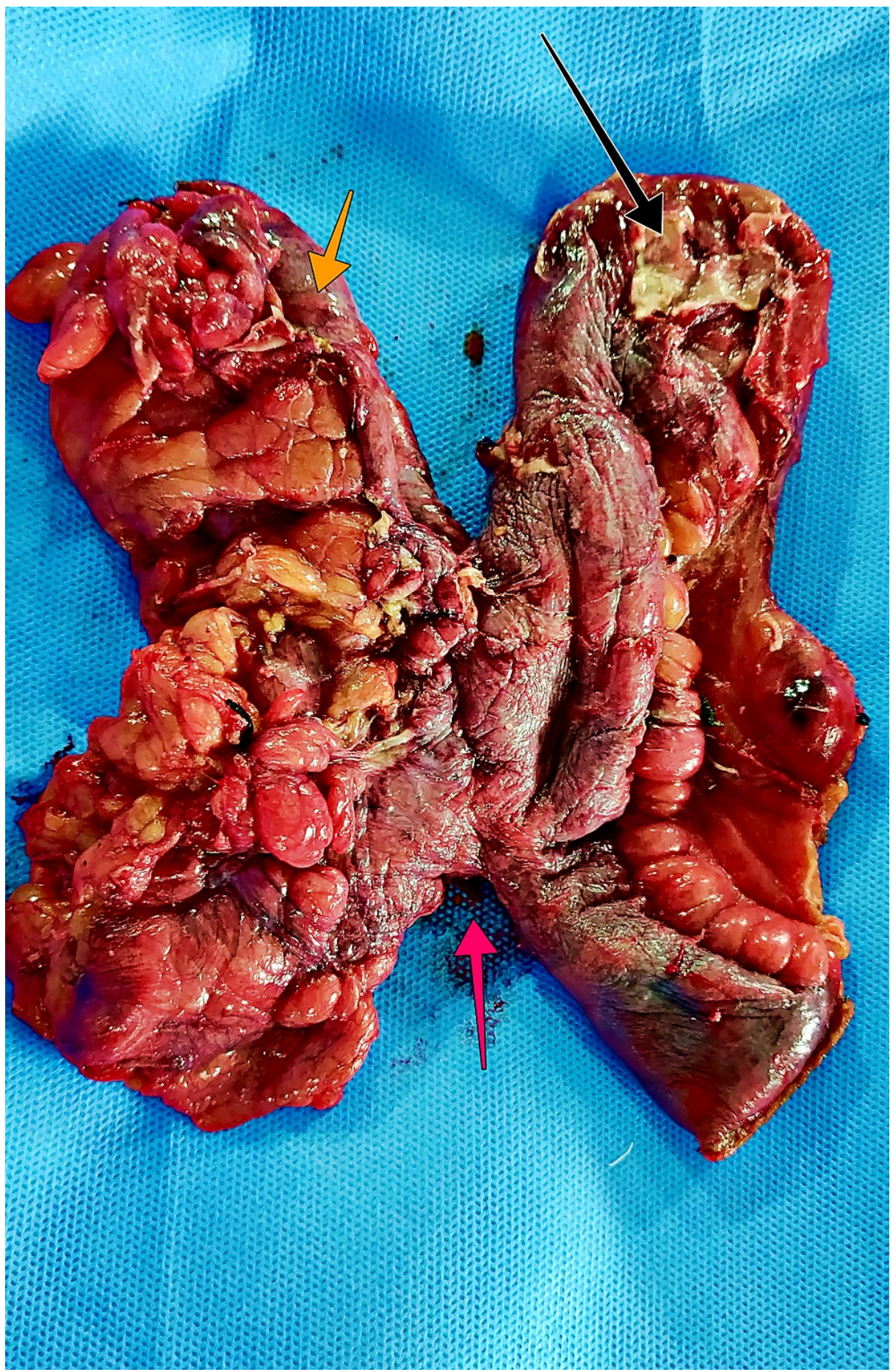

\section{FIGURE 3: Resected specimen.}

Black arrow - Dilated ileal blind loop with pus flakes and perforation. Yellow arrow - Colonic blind loop. Red arrow - Side-side anastomosis.

Resection of the previous anastomotic site and a redo functional end-to-end (anatomical side-to-side) ileotransverse anastomosis was done using a linear stapler. The postoperative course was uneventful. The patient was discharged on a regular diet on the sixth postoperative day.

\section{Discussion}

Bowel continuity, post intestinal resection, can be restored in different anatomical configurations by various surgical techniques. End-to-end anastomosis is the most physiological but has complications like increase risk of anastomotic leak due to devascularization of ends of the bowel during mesenteric dissection and discrepancies in bowel circumference like during ileocolic anastomosis [3]. There has been an increase in 
side-to-side lateral anastomosis owing to the popularity of linear staplers. Though it is an easy, fast, accurate, and reliable technique of re-establishing intestinal continuity, it is not without complications [3]. An excess segment of the bowel left distal to the anastomosis starts the vicious cycle of a blind pouch. Circular muscle fibers that get divided during such a side-to-side anastomosis can result in local dysmotility with stasis of enteric content and enterolith formation. Subsequent progressive distension causing thinning of the blind pouch's wall coupled with bacterial overgrowth causing inflammation and mucosal ulceration may lead to bleeding or bowel perforation [4]. However, not all blind pouches are symptomatic. There are reports of incidental long blind loops discovered during autopsy studies or surgical interventions [5]. Comorbidities like diabetes [6], amyloidosis [7], scleroderma, hypothyroidism [8] disrupt intestinal motility and therefore promote bacterial overgrowth, thus adding to the effect of the anatomical anomaly [9]. In the current case, the patient had diabetes.

After an extensive literature search, 14 cases of pinpoint perforation of blind pouches were found, presenting with signs and symptoms of peritonitis [5,10-12]. BLS has a delayed presentation after the sideto-side anastomosis. According to a review by Frank et al. published in 1990, most patients with symptomatic blind pouch presented more than five years after the surgery [11]. In another series of three patients, patients presented with blind loop perforation around two years after the surgery [12].

Diagnosis of BLS is challenging and requires a high level of clinical suspicion. Patients can present with chronic diarrhea, steatorrhea, vitamin B12 deficiency causing megaloblastic anemia, and other nutritional deficiencies [13]. A patient with a history of side-to-side intestinal anastomosis, presenting with spontaneous onset of acute abdominal pain and diarrhea with or without signs of peritonitis, should be suspected with BLS. An X-ray may or may not show pneumoperitoneum. Therefore, such patients should undergo further cross-sectional imaging. On CECT, a blind pouch is seen as a saccular enteric structure with thickened walls, with surgical staples seen nearby [14]. In cases with blind pouch perforation, there might be evidence of enteroliths and surrounding collection around the cul-de-sac with extra-luminal air foci [12].

The possibility of creating a blind pouch should be kept in mind while doing a side-to-side anastomosis. The length of end loops distal to anastomosis should be kept minimum, preferably closing the loops just distal to the lateral anastomosis. In symptomatic cases, excision of the diseased segment and re-anastomosis, preferably in an end-to-end fashion, should be performed [15]. Limited resection of the diseased pouch can also be attempted without the need for a resection anastomosis depending on the condition of the diseased segment [12]. An end-to-end anastomosis, despite its limitations, is free from the complication of BLS [3]. In a retrospective analysis of ileocolic anastomosis, nine distended blind loops were identified in 31 side-toside anastomoses, whereas no blind loops were observed after 12 end-to-end anastomoses [16].

\section{Conclusions}

In the era of stapled intestinal anastomosis, the possibility of a BLS occurring after a side-to-side anastomosis should not be neglected. Though this is a well-established long-term complication, traditional surgical textbooks have not given much importance to it till now. For prevention of BLS, the length of end loops distal to anastomosis should be kept minimum. In symptomatic cases, excision of the diseased segment and re-anastomosis, preferably in an end-to-end fashion, should be performed.

\section{Additional Information}

\section{Disclosures}

Human subjects: Consent was obtained or waived by all participants in this study. Conflicts of interest: In compliance with the ICMJE uniform disclosure form, all authors declare the following: Payment/services info: All authors have declared that no financial support was received from any organization for the submitted work. Financial relationships: All authors have declared that they have no financial relationships at present or within the previous three years with any organizations that might have an interest in the submitted work. Other relationships: All authors have declared that there are no other relationships or activities that could appear to have influenced the submitted work.

\section{References}

1. Townsend CM: Sabiston Textbook of Surgery. Elsevier Health Sciences, 2021.

2. Yeo CJ: Shackelford's Surgery of the Alimentary Tract . Elsevier Health Sciences, 2017.

3. Cannon WB, Murphy FT: The movements of the stomach and intestines in some surgical conditions . Ann Surg. 1906, 43:512-536. 10.1097/00000658-190604000-00004

4. Lappas JC: Imaging of the postsurgical small bowel. Radiol Clin North Am. 2003, 41:305-326. 10.1016/s0033-8389(02)00119-7

5. Schlegel DM, Maglinte DD: The blind pouch syndrome. Surg Gynecol Obstet. 1982, 155:541-544.

6. Meldgaard T, Keller J, Olesen AE, et al.: Pathophysiology and management of diabetic gastroenteropathy . Therap Adv Gastroenterol. 2019, 12:1756284819852047. 10.1177/1756284819852047

7. Matsumoto T, Iida M, Hirakawa M, et al.: Breath hydrogen test using water-diluted lactulose in patients with gastrointestinal amyloidosis. Dig Dis Sci. 1991, 36:1756-1760. 10.1007/BF01296621

8. Ebert EC: The thyroid and the gut. J Clin Gastroenterol. 2010, 44:402-406. 10.1097/MCG.0b013e3181d6bc3e 


\section{Cureus}

9. Rao SC, Bhagatwala J: Small intestinal bacterial overgrowth: clinical features and therapeutic management . Clin Transl Gastroenterol. 2019, 10:e00078. 10.14309/ctg.0000000000000078

10. Tsugu Y, Shimada N, Kawakami H, Kadomatsu T, Morita H: Blind loop syndrome after intestinal anastomosis (case of perforated blind loop). Shujutsu. 1966, 20:650-656.

11. Frank P, Batzenschlager A, Philippe E: Blind-pouch syndrome after side-to-side intestinal anastomosis . Chirurgie. 1990, 116:586-596.

12. Valle RD, Zinicola R, Iaria M: Blind loop perforation after side-to-side ileocolonic anastomosis . World J Gastrointest Surg. 2014, 6:156-159. 10.4240/wigs.v6.i8.156

13. Botsford TW, Gazzaniga AB: Blind pouch syndrome a complication of side to side intestinal anastomosis . Am J Surg. 1967, 113:486-490. 10.1016/0002-9610(67)90192-4

14. Sandrasegaran K, Maglinte DD, Rajesh A, Tann M, Kopecky KK: CT findings for postsurgical blind pouch of small bowel. Am J Roentgenol. 2006, 186:110-113. 10.2214/AJR.04.1628

15. Killingback M: Blind Pouch Syndrome After Bowel Resection. Colorectal Surgery. Springer, New York; 2006. 12-13. 10.1007/0-387-36941-4 6

16. Stellamor K, Hochberger O: To the cognizance of the "blind pouch syndrome" following intestinal anastomoses (author's transl). Rontgenblatter. 1974, 27:82-90. 